NBER WORKING PAPER SERIES

\title{
GOVERNMENT POLICY AND LABOR SUPPLY WITH MYOPIC OR TARGETED SAVINGS DECISIONS
}

\author{
Louis Kaplow \\ Working Paper 21109 \\ http://www.nber.org/papers/w21109 \\ NATIONAL BUREAU OF ECONOMIC RESEARCH \\ 1050 Massachusetts Avenue \\ Cambridge, MA 02138 \\ April 2015
}

Harvard University and National Bureau of Economic Research. I thank Jeffrey Brown for comments, Andrea Lowe for research assistance, and Harvard University's John M. Olin Center for Law, Economics, and Business for financial support. More formal analysis of much of part II's treatment of myopia appears in Kaplow $(2006,2015)$ and of part III's examination of targeted savings in Kaplow (2011). Those analyses and the current essay grew out of my work on the chapters addressing capital taxation and social security in Kaplow (2008), which also addresses additional subjects, some related to those examined here. The views expressed herein are those of the author and do not necessarily reflect the views of the National Bureau of Economic Research.

Louis Kaplow occasionally consults on antitrust cases, and his spouse is in the legal department of a financial services firm.

NBER working papers are circulated for discussion and comment purposes. They have not been peerreviewed or been subject to the review by the NBER Board of Directors that accompanies official NBER publications.

(C) 2015 by Louis Kaplow. All rights reserved. Short sections of text, not to exceed two paragraphs, may be quoted without explicit permission provided that full credit, including $\mathbb{C}$ notice, is given to the source. 
Government Policy and Labor Supply with Myopic or Targeted Savings Decisions

Louis Kaplow

NBER Working Paper No. 21109

April 2015

JEL No. D11,D91,H21,H24,H31,H55,J22,J26

\begin{abstract}
A central justification for social insurance and for other policies aimed at retirement savings is that individuals may fail to make adequate provision during their working years. Much research has focused on myopia and other behavioral limitations. Yet little attention has been devoted to how these infirmities, and government policies to rectify them, influence labor supply. This linkage could be extremely important in light of the large pre-existing distortion due to income and consumption taxation and income-based transfer programs. For example, might myopic individuals, as a first approximation, view payroll taxes and other withholding to fund retirement savings as akin to an income tax, while largely ignoring the distant future retirement benefits that they fund? If so, the distortion of labor supply may be many times higher than otherwise, making savings-promotion policies much more costly than appreciated. Or consider what may be the labor supply implications for an individual who is defaulted into higher savings and, as a consequence, sees concomitantly lower take-home pay. This essay offers a preliminary, conceptual exploration of these questions. In most of the cases considered, savings policies do not act purely like a tax despite individuals' non-optimizing savings behavior, and in some cases labor supply actually is raised, not lowered, in which event policies that boost savings may be significantly more welfare-enhancing than recognized. Accordingly, there is a compelling need for empirical exploration of the interaction between nonoptimal savings behavior and labor supply.
\end{abstract}

\author{
Louis Kaplow \\ Harvard University \\ Hauser 322 \\ Cambridge, MA 02138 \\ and NBER \\ meskridge@law.harvard.edu
}




\section{Introduction}

Substantial government policies are motivated, at least in significant part, by the concern that individuals, left to themselves, may fail to provide adequately for their retirement. ${ }^{1}$ Social insurance programs are the most substantial. ${ }^{2}$ All tax policies implicating savings are also relevant, including provisions such as IRAs and 401(k) plans that specifically aim to encourage retirement savings. In addition, regulation under ERISA is increasingly concerned with encouraging savings, such as by permitting employers to default their employees into significant withholding to fund retirement accounts.

Why might individuals’ savings decisions be inadequate? An important body of work, which has helped fuel the growth of behavioral economics in the past two decades, addresses this question. ${ }^{3}$ One important strand focuses on myopia, with roots tracing back to Strotz (1956). As developed by Laibson (1996, 1997), Thaler and Benartzi (2004), and others, it appears that individuals often overweight the present relative to the future, succumbing to the immediate temptation of additional consumption. Laibson (1996) estimated that the correction of savings inadequacies due to myopia could raise individuals' lifetime welfare by an amount equal to almost an additional year's worth of income. If individuals indeed overweight the here and now, it would raise their utility if they were led to save more for the future.

Another important strand of the literature, for example, Bernheim (1994) and Diamond (2004), expresses the concern that savings optimization is a complex and daunting task, one that may lead to significant errors, avoidance of the problem, or satisficing responses. See, for example, Beshears et al. (2013) on complexity and participation rates; Carroll et al. (2009) on active decision requirements and participation rates; Johnson, Kotlikoff, and Samuelson (2001) offering experimental evidence of the complexity of the decision-making problem; and Gokhale, Kotlikoff, and Warshawsky (2001) on oversimplification in common financial planning software. Unlike with myopia, this broader set of concerns does not have sharp implications for how individuals will actually make their savings decisions. An important possibility is that they may engage in what may be described as targeted savings behavior, essentially pursuing a course that is dictated or recommended by others. For example, research by Madrian and Shea (2001), Choi et al. (2004), and Chetty et al. (2014), along with additional work surveyed by Beshears et al. (2008), demonstrates employees' tendency to be influenced by employers' default rules. This pertains not only to the choice of how much to save also to how those savings are invested. Such behavior suggests that many individuals may not be optimizing in any direct sense - which is

\footnotetext{
${ }^{1}$ Empirical evidence on the adequacy of individuals' retirement savings is conflicting, although it must be noted that, to the extent most individuals' overall savings are adequate, such may reflect the existence of social insurance, retirement savings subsidies, and other policies. See, for example, Kotlikoff, Spivak, and Summers (1982), Banks, Blundell, and Tanner (1998), Engen, Gale, and Uccello (1999), Moore and Mitchell (2000), Bernheim, Skinner, and Weinberg (2001), Aguiar and Hurst (2005, 2007), Scholz, Seshadri, and Khitatrakun (2006), and Smith (2006).

${ }^{2}$ Some countries mandate private retirement schemes alongside or in place of government social insurance (see Bateman, Kingston, and Piggott 2001), which would be subject to similar analysis.

${ }^{3}$ For surveys, see Bernheim (2002) and Bernheim and Rangel (2007).
} 
assumed to be the case under myopia, albeit with a present-oriented bias - but rather are responding to advice and other cues without undertaking an independent assessment.

By contrast to the increasing attention to and insight about individuals' savings decisions and also government policies that may ameliorate savings inadequacy, little work has been devoted to the implications of these features of behavior and the related policy responses for individual' labor supply decisions. ${ }^{4}$ The implicit, largely unexamined assumption is that these matters relating to savings have little or no effect on labor supply, as if it were an entirely separate matter. This stance, however, is problematic.

First, labor supply is just too important to ignore. Income taxes, consumption taxes, and income-based transfer programs cause a substantial downward distortion of labor supply. This distortion had been central in the last half century of literature on optimal income taxation and much work on second-best government policies; in addition, the elasticity of taxable income is viewed as one of the most important, policy-relevant empirical parameters. The sheer magnitude of the phenomenon, as well as pure intellectual curiosity, demands attention to possible interactions. Moreover, even if any feedbacks on labor supply prove to be modest, they still may be significant due to the large pre-existing distortion. Indeed, such labor supply effects could be as or more important for overall welfare than are the direct effects of savings-related policies on savings. Therefore, in accord with the central theme of my book on taxation and public economics (Kaplow 2008), it is presumptively important for researchers to take an integrated approach to the analysis of interactions among different policy instruments - here, those relating to savings and those burdening labor income.

Second, there is every reason to believe that induced or forced savings may affect labor supply. Why, after all, do individuals work? It is assumed that most people, particularly with regard to additional marginal effort, offer their services in order to fund their consumption. And, since it is the perceived marginal value of consumption that individuals trade off with the marginal disutility of labor, it is natural to suppose that labor supply may be affected. When government policies alter individuals' savings decisions, they will tend, in general, to alter individuals’ perceived value of consumption, and thus labor effort.

To further motivate this point, consider a simple example: Suppose that individuals are myopic and, as a consequence, the government implements an actuarially fair forced-savings program under which a payroll tax is charged in the present to finance distant future retirement benefits. What if, as a first approximation, individuals treat the forced contributions as tax payments and essentially ignore the benefits that accrue much later? Then the effect on labor

\footnotetext{
${ }^{4}$ For work on other dimensions, see Auerbach and Kotlikoff (1987), Browning (1985), Burkhauser and Turner (1978, 1985), Diamond (2002), Gordon (1983), Moffitt (1987), and the survey by Feldstein and Liebman (2002). See also Liebman and Luttmer (2012), who offer survey evidence regarding the extent to which workers perceive the actual tax-benefit linkage in social security, and Liebman and Zeckhauser (2004) on the possibility that, due to limited understanding, individuals' behavior may be more governed by average than marginal tax rates. For work on other aspects of myopia, see Diamond and Köszegi (2003) and Feldstein (1985).
} 
supply will be akin to that of an additional tax on labor income (despite the hypothesized perfect tax-benefit linkage). Now, assume further that this government, like many OECD countries, imposes payroll taxes for social insurance that are of similar magnitude to income taxes. Then, following the crude rule of thumb that distortion rises with the square of the tax rate, the forcedsavings program effectively doubles the marginal tax rate and hence quadruples the distortionary cost of taxation. ${ }^{5}$

The clear lesson - even if one considered a gentler example - is that effects of government savings policies on labor supply may be of first-order importance. The additional costs could swamp the savings benefits, particularly with regard to expansions, once the extremes of undersavings are mitigated. We will also see that there are plausible scenarios in which stronger savings requirements increase, rather than reduce, labor supply. In such cases, savings policies could be much more attractive than meets the eye. Even a modest boost to labor supply could be significantly beneficial - and more consequential for social welfare than any improvement in savings per se - due to the large pre-existing labor supply distortion.

This paper offers a conceptual exploration that aims to illuminate some of the most important possible effects of government savings policies on labor supply when individuals' savings decisions are not optimizing in the neoclassical sense. Because there has been little previous exploration - and almost no relevant empirical work - the strategy is to consider a range of plausible conjectures and trace their implications. We will see that, in some cases considered, powerful and sometimes counterintuitive results emerge. Most cases, it turns out, are quite different from the foregoing illustration. In certain scenarios, infirmities in savings decisions imply that savings policies boost labor supply; in others, labor supply is reduced; and in one, there is no effect. In addition, which case governs and the magnitude of the effects depend in large part on factors that have not previously been identified. As a consequence, there is a significant need for empirical research, and this essay aims to outline part of the appropriate research agenda.

The analysis begins in part II, which addresses the effect of government policy when individuals' savings decisions are myopic. First, it introduces a simple, two-period model that will be employed throughout this essay. The interpretation is that the first period consists of the working years of an individual's life - when labor is supplied, a fraction of disposable income is consumed, and the remaining fraction is saved - and the second period the retirement years when the savings are consumed. Myopia involves of the individual placing too much weight on first-period consumption relative to that in retirement.

\footnotetext{
${ }^{5}$ In fact, some of the literature that seeks to quantify the deadweight cost of existing U.S. taxes (see, for example, that surveyed in Fullerton (1991)) treats payroll taxes that fund social insurance benefits as pure additions to the income tax, which treatment is correct in the example described in the text but turns out to be improper in most of the cases examined below.
} 
Much of the analysis in this part examines social security, taking a simple and pure form that consists solely of a forced-savings policy (thereby abstracting from redistribution, government debt, and other issues). If the only effect of such a forced-savings program was to increase savings, social security would raise welfare up to the point that the degree of mandatory savings just equaled what would have been optimal for individuals to save, that is, what they would have saved in the absence of myopia.

Next, we turn to our central question of how such forced savings may affect labor supply. Precisely because we have assumed that individuals' savings are myopic, we cannot answer this question in a neoclassical fashion. Instead, more needs to be said about how myopic savers might think about their labor supply decisions. As mentioned, individuals work in order to consume, and we are supposing both that they are myopic when undertaking consumption and that the government is forcing them to save more. The first case considered is one in which individuals are naïve in the sense that their labor supply decisions are governed by the same "behavioral" utility function that governs their (myopic) savings decisions. When the social security forced-savings requirement just begins to bind - as it just crosses the threshold savings level that even our myopic individuals would have chosen in any event - there is no effect on labor supply (in sharp contrast to the pure case of adding a small tax on top of a pre-existing tax). As the constraint binds further, labor supply falls when the pertinent parameter is in the range associated with an upward-sloping labor supply curve (i.e., one in which an ordinary income tax reduces labor supply). In this setting, the dominant force is that naïve individuals perceive their consumption to be less valuable, and hence they have less incentive to work.

Next it is supposed that individuals are sophisticated in the sense that, when choosing labor supply, they are aware of their proclivity to consume too much in the present. (This assumption, like the preceding one, is of a sort commonly explored in the behavioral economics literature, although the empirical validity of neither assumption has been assessed in the present context.) Here, there is an immediate impact on labor supply as the forced-savings constraint just begins to bind - that is, a first-order effect, the magnitude of which, however, falls as the constraint becomes tighter. The sign of this effect is opposite to that in the prior case. That is, in the parameter range in which labor supply is upward sloping, individuals' labor supply rises, providing a partial offset to the pre-existing distortion of labor supply. Sophisticated individuals, in contrast to those who are naïve, appreciate that the forced-savings requirement is combating their myopia, and hence they find work more rewarding than otherwise.

Finally, myopia is considered with regard to capital taxation and subsidization, a particular motivation being that a savings subsidy may seem appealing when individuals are myopic. When savings are examined in isolation, subsidizing savings helps offset the effect of myopia, raising individuals' utility. Labor supply is another matter. Starting from the point of neutrality, introducing a small savings subsidy has effects on labor supply qualitatively similar to those from forced savings: naïve individuals have no first-order response, and sophisticated individuals raise labor supply in the parameter range with upward-sloping labor supply. 
Part III turns attention to additional sorts of behavioral infirmities, under the rubric of targeted savings. The myopic individuals in part II were assumed to optimize, just with an excessive weight on the present. Here, we consider individuals who do not explicitly calculate with regard to their savings decisions. Instead, they hit some target, perhaps just sticking with how much savings is forced or how much their employer contributes to their retirement plan, perhaps allowing a default to stick, perhaps following advice from investment advisors or other sources, or perhaps just mimicking others' behavior. The idea is that they take this externally supplied target as the beginning and end of their savings decision. Although this assumption might be extreme, it may have a key element of truth for many individuals.

Although some of these phenomena have been studied, as mentioned above, it is difficult to connect them with labor supply. The challenge, in essence, is that if an individual is not thinking very hard about how much to consume now versus save for later, how do we imagine that the same individual thinks about the result of this allocation decision when choosing labor supply? Consider, for example, an individual who sticks with a default voluntary contribution. When contemplating whether to take a job, change jobs, how much to work, and so forth, does this individual just ignore what is saved? And, if not, how is it taken into account? If the default had been set at a higher level, how would labor supply differ?

Obviously, little is known about the answer to such questions, and undoubtedly the answers vary across individuals. Accordingly, a range of assumptions is explored. One possibility is that the savings are treated as if they just vanish, as would be the case if an individual looks solely at take-home pay and ignores everything else. Then any added savings would affect labor supply as would an additional tax (levied on top of the existing labor income tax), and this would be so even if the added savings were at some point elected by that very individual. Another possibility is that the individual - aware that the saved funds are his or her own, but unsure of how they should be valued (that was the problem in the first place) - values them roughly as if they had been available for present consumption. In this case, raising the savings target has no effect on labor supply. A third possibility is that the individual regards the target as paternalistic, in the favorable sense that someone (the government, the employer, the investment advisor) has roughly figured out how much it is best to save and dictated that fraction of current earnings. In this case, it will be explained that the effect of a higher savings target is to raise labor supply. Combining the cases, we can see that, as with myopia, policies that affect savings targets can have important effects on labor supply, and there exist plausible cases in which the effects are positive and in which they are negative.

Part IV briefly explores additional issues. First, attention is given to the choice among savings policies when individuals are myopic or engage in targeted savings. Second, some assessment is offered of liquidity constraints that bind early in life. Third, it is explained how the present analysis can be applied fairly directly to forms of social insurance other than retirement savings, notably, health insurance, disability insurance, and unemployment insurance - and to employer provision of such other types of insurance. 
Part V concludes. The central emphasis is on the need for empirical research on how savings policies affect labor supply, including with regard to how these effects may vary across individuals who make their savings decisions differently and, for a given savings decisionmaking process, how the same individuals regard their savings choices when making labor supply decisions. As mentioned at the outset, effects on labor supply can be first-order and hence can have major implications for the optimal design of government savings policies. Accordingly, the growing body of insightful empirical research and policy analysis of nonneoclassical savings decisions needs to be broadened to encompass labor supply.

\section{Myopia}

\section{A. Model}

This essay uses a simple, two-period model to develop most of the analysis. ${ }^{6}$ As explained in the introduction, the first period can be thought of as an individual's working years and the second period as retirement. In the first period, individuals choose a level of labor effort $l$, earning a before-tax income of $w l$, where $w$ is their wage rate. They are subject to a linear income tax at the rate $t$. (The use of government funds is outside the model and taken as given.) They allocate their after-tax income between current consumption, $c_{1}$, and savings. Their savings earn interest at the rate $r$, and the resulting balance (savings times $1+r$ ), denoted $c_{2}$, is consumed in period 2.

Individuals' utility is assumed to take the following form:

(1) $u\left(c_{1}, c_{2}, l\right)=\frac{c_{1}{ }^{1-\rho}}{1-\rho}+\delta \frac{c_{2}{ }^{1-\rho}}{1-\rho}-z(l)$.

The first two terms correspond to utility from first- and second-period consumption, respectively, and the final term is the disutility from supplying labor, taken to be positive (which is why it is subtracted) and increasing at an increasing rate: $z^{\prime}>0, z^{\prime \prime}>0$. The functional form for each period's utility from consumption is constant relative risk aversion, with $\rho$ being the risk aversion parameter (and it is further understood that, when $\rho=1$, utility from consumption $c_{i}$ is given by $\ln c_{i}$ ). A higher $\rho$ means that individuals' marginal utility of consumption falls more rapidly. Note that this overall functional form further implies that there is a constant elasticity of intertemporal substitution in consumption equal to $1 / \rho$.

Finally, the factor $\delta$ refers to individuals' true subjective discount factor. This factor should be contrasted with myopia, which will be introduced momentarily. The parameter $\delta$ is meant to indicate a true and proper discount rate. Even individuals who are forward-looking,

\footnotetext{
${ }^{6}$ For additional formal details throughout this part, see Kaplow (2006, 2008, 2015).
} 
have complete self-control, and are entirely rational may weight future consumption differently from that in the present. Perhaps because of different circumstances in working versus retirement years, consumption is more valuable in one period or the other, and perhaps the future is discounted for the probability of no longer being alive. In any event, the factor $\delta$ is included here merely for completeness; it plays no special role in what follows. It is the present-focused deviation from this true discount rate involved with myopia that is our concern.

To introduce myopia, consider the following altered, "behavioral” utility function (so called because this utility function determines myopic individuals’ savings behavior, whereas expression 1 indicates their true, actually experienced utility):

(2) $u^{M}\left(c_{1}, c_{2}, l\right)=\beta \frac{c_{1}^{1-\rho}}{1-\rho}+\delta \frac{c_{2}{ }^{1-\rho}}{1-\rho}-z(l)$.

For convenience, this will also be referred to as myopic utility, $u^{M}$, because this is the level of utility perceived by an individual acting myopically. The weight $\beta$ on the first term, taken to exceed 1 for myopic individuals, indicates the degree to which they overweight present consumption. $^{7}$ Note importantly that, although in a formal sense the introduction of the weight $\beta$ in expression (2) may seem redundant of the true discount factor $\delta$, in the analysis to follow we will be comparing consumption and also labor supply behavior governed by expression (2) versus expression (1). That is, the analysis takes $\delta$ to be constant (it is present in the background, just for completeness, as mentioned above), whereas the value of $\beta$ is assumed to exceed 1 in expression (2) whereas it implicitly equals 1 in expression (1), and this difference is our indication of the extent of myopia.

(As one further technical note, readers familiar with the literature on myopia will recognize that a model with three or more periods is required to empirically identify myopia as distinct from standard discounting, but this essay takes myopia as given and examines its consequences for labor supply, wherein a two-period model is more transparent and also is sufficient to identify important forces. Nevertheless, extending the analysis to additional periods would be illuminating, as it would allow one to study retirement decisions and to identify additional subtleties. ${ }^{8}$ )

\footnotetext{
${ }^{7}$ It is more conventional to place a weight of less than one on second-period consumption, but the effect is the same and the notation is a bit clearer this way for those unfamiliar with such models. One could also weight the disutility of labor by $\beta$, but this would not affect the analysis qualitatively.

${ }^{8}$ Regarding the former, quasi-hyperbolic discounting is taken to imply excessive weight on the first period compared to later periods - with no such excessive weighting, say, favoring period two over period three, when viewed from the vantage point of period one. Consequently, at least three periods are necessary to empirically distinguish myopia and standard discounting. The formal extension to three or more periods, which is indeed valuable, would require further (cross-period) assumptions regarding the relationship between myopia and labor supply that are more subtle than those employed here (and hence more heroic, in the absence of empirical evidence).
} 
Returning now to the exposition of the model, it remains to state individuals’ budget constraint:

(3) $c_{1}+\frac{c_{2}}{1+r}=(1-t) w l$.

On the left side, we have the present value of individuals' lifetime consumption expenditures. Because amounts saved in period one earn interest at the rate $r$ and thus grow to $1+r$ in period 2, this means that a dollar of second period consumption only costs $1 /(1+r)$ dollars of saved, firstperiod, disposable income. On the right side, we have the individual's earnings, $w l$, weighted by the factor $1-t$ because the fraction $t$ must be paid in taxes. ${ }^{9}$

Nonmyopic individuals maximize $u$ given by expression (1), subject to this budget constraint (3). Myopic individuals maximize $u^{M}$ given by expression (2), subject to this budget constraint. Focusing on the consumption decision (that is, for any given, common level of labor supply and thus of disposable income), it is clear that myopic individuals will save less, consuming more in period one. The greater their myopia, the more skew will be present. We now examine the effects of a forced-savings requirement, such as through social insurance.

\section{B. Social Security with Naïve Labor Supply}

Social security will be modeled here as a forced minimum savings constraint, or, equivalently, a ceiling on the portion of disposable income that may be spent on current consumption. As indicated in the introduction, it is useful to abstract from additional considerations such as the use of social insurance for redistributive purposes (on which, see Kaplow 2008) and the question whether social insurance obligations should be funded currently by the government.

Specifically, let $\alpha$ denote the fraction of disposable income that individuals must save, which we can suppose is implemented with a payroll tax, the proceeds of which grow at the rate $r$ and are disbursed during retirement. Accordingly, the constraint on first-period consumption is

(4) $c_{1} \leq(1-\alpha)(1-t) w l$.

When social security is taken to be an actuarially fair forced-savings requirement, neoclassical optimizing behavior implies that it cannot have any effect on labor supply (or anything else) until the point at which forced savings exceed the amount that individuals would otherwise have chosen. We are, however, interested in myopic savings behavior and, regarding expression (4),

\footnotetext{
${ }^{9}$ It would be straightforward to allow this linear income tax to have a nonzero intercept, that is, to have some or all of the tax revenue rebated equally to all individuals (thereby producing what is more familiarly understood as a negative income tax). Such a modification could also serve as a shorthand for the presence of virtual income in a nonlinear scheme (although further complications would arise with a nonlinear income tax). There would be little qualitative effect on the results (see Kaplow 2006, 2008, 2015). For further analysis of how the presence of unearned income influences the values of $\rho$ for which labor supply is upward sloping, see Chetty (2006).
} 
with levels of $\alpha$ that are high enough to reduce first-period consumption below the excessive level that would be chosen by myopic individuals who maximize $u^{M}$ (expression 2) rather than $u$ (expression 1).

In this range, the constraint (4) binds, and, if the only effect were on the individual's savings, welfare would rise because of the reduction in the extent to which first-period consumption is excessive. The reason is that myopic individuals, in allocating too much consumption to the first period, thereby depress the marginal utility of consumption in the present and likewise raise the marginal utility of future, retirement consumption. Once the constraint binds, dollars are moved from the present, low-true-marginal-utility period to the future, high-true-marginal utility period. The benefit of this forced reallocation is greatest when the constraint just begins to bind and is falling thereafter, reaching zero when forced savings equals the nonmyopic optimal level of savings. (Throughout, it will be assumed that individuals cannot or will not borrow against their future social security retirement payouts, which would undermine the effect of the constraint.)

We now reach our central question of whether and how such a forced-savings requirement may affect labor supply. The key challenge is that we need to know more about how the individual chooses labor supply. In the neoclassical case, the answer is straightforward: the individual chooses both labor supply and the consumption allocation to maximize $u$ (expression 1) subject to the budget constraint (expression 3). But here we have assumed that the individual maximizes $u^{M}$ (expression 2), not $u$, when allocating consumption between the present and the future, so we confront the question: Which form of utility - true or myopic does the individual maximize when choosing labor supply? Or, perhaps, does the individual do something else altogether? Some assumption must be made, and ultimately we need to know empirically how myopic savers behave in this regard. Because the answer is not presently known, two basic and fairly different assumptions will be explored here.

First, suppose that our myopic savers are naïve in the following sense: when choosing their labor effort, they maximize $u^{M}$ (expression 2), the same utility function that they will use when allocating their consumption between the present and the future. One might say that they only know this one utility function, their so-called behavioral utility function. This seems to be a natural starting point and to be plausible with regard to some aspects of labor supply. Suppose, for example, that an individual is deciding whether to work overtime or instead to leave at 5 p.m. in order to spend time with friends or to watch a television program or a favorite sporting event. The same desire for immediate gratification that contributes to myopic spending out of one's paycheck may lead the individual to lean excessively toward forgoing the overtime pay. Without making any empirical claim with regard to this suggestion, this section proceeds to consider its implications for labor supply.

As $\alpha$ is raised to and past the point at which the forced-savings constraint (4) just begins to bind, our myopic individual's current consumption is forced down, below the level that he or 
she perceives to be best, in favor of savings for retirement consumption. The myopic individual considers this to be detrimental because, after all, this is not what he or she understands to be optimal.

To analyze this further, let us first focus on where the constraint just begins to bind. At this point, our myopic individual is actually indifferent as the first dollar is forcibly reallocated from the present to the future. It is in the nature of an optimum that the individual regarded the perceived marginal utility of present consumption to equal that of future consumption (adjusted for the fact that savings grow at the rate $r$ ). Thus, at the outset, the reduction in first-period consumption reduces perceived utility by the same amount that the increase in second-period consumption raises perceived utility. Furthermore, this indifference implies that the overall marginal utility of earning an additional dollar is unchanged. (As just explained, the fact that an infinitesimal fraction of the after-tax income from that incremental dollar must be allocated to savings rather than to current consumption is a matter of indifference.) The immediate implication is that the incentive to supply labor is unchanged, so labor supply is unchanged.

This seemingly bland conclusion is from one perspective remarkable: the effect of social security on labor supply is not remotely like that of a tax levied on top of an existing tax. If the labor income tax rate is raised slightly from its current level, say, it is lifted from $30 \%$ to $31 \%$, the effect on labor supply is first order. We have a large pre-existing tax, which causes a significant downward distortion of labor supply. From there, even a tiny increase in the tax rate will, at the margin, cause a first-order welfare loss, the magnitude of which is determined by the pre-existing (large) marginal tax rate. By contrast, here, when we raise $\alpha$ just past the point at which the forced-savings constraint (4) begins to bind, we are raising the payroll tax and yet are causing no further distortion of labor supply. (Note also that $\alpha$ itself was already well above zero at that point but has had no labor supply effect because the constraint was not yet binding.) Moreover, this result holds no matter how great is our individual's myopia. Hence, we have seen that the story in the introduction - which imagines, as an approximation, that a highly myopic saver might view the payroll tax as a pure tax, ignoring distant future benefits - is not at all correct in this case.

The explanation for this large contrast is that even our myopic individual places some value on future savings. In addition, the perceived marginal value of such savings is significant. On one hand, it is suppressed to the extent of myopia, but, on the other hand, that very myopia leads to an initial allocation away from the future, which raises the actual and perceived marginal utility of future consumption. In addition, the excess allocation toward the present suppresses the marginal utility of current consumption. Bringing all of this together, we have the above point that our myopic individual - no matter how myopic - will have equated the perceived marginal utility of present and future consumption at the margin (again, adjusted for the fact that savings earn interest of $r$ ). Hence, a slight reallocation from that point has no first-order effect. 
Next let us consider higher levels of $\alpha$, above the level at which the constraint (4) just begins to bind. We are now in a range in which our myopic individual's perceived optimal consumption allocation no longer holds. Instead, from this individual's perspective, there is too much consumption in the future and not enough in the present. Our individual dislikes this state of affairs, but what implication does this carry for labor supply?

The answer involves two competing effects, which will be labeled direct and indirect (although this labeling should not be taken to imply, a priori, that the former necessarily exceeds the latter). The direct effect is negative: because our individual cannot allocate an additional dollar of earned (after-income-tax) income as he or she wishes, labor supply at the margin is less attractive. This depresses labor effort.

The indirect effect is more subtle but nevertheless important. From our myopic individual's point of view, consumption is too low in the present and too high in the future as a consequence of the binding forced-savings requirement. Under the utility function, $u^{M}$ (expression 2), perceived marginal utility is consequently higher in the present and lower in the future. Therefore, when the individual earns an additional dollar of disposable income, some of it (less than the individual would like, to be sure) is allocated to the present, which has more utility punch than otherwise, and some is allocated to the future, which has less punch. For standard functional forms for individual utility, including that employed here, the former effect exceeds the latter. Put another way, our myopic individual's desire for more consumption in the present is necessarily heightened by more than the individual's wish for additional consumption in the future is suppressed. And the only way our constrained myopic individual can meet this heightened desire for greater present consumption is to work harder. As the forced-savings constraint becomes tighter, the magnitude of this effect increases. Therefore, the indirect effect encourages labor effort.

Which effect is greater? The answer depends on the curvature of individuals' utility functions. When curvature is greater, the magnitude of the marginal utility effect just described is larger, making the indirect effect on labor supply larger. In this simple model (and with our specific functional forms for utility and for the tax system), it turns out that the former, direct effect dominates - that labor supply falls - precisely in those cases in which labor supply is upward sloping, which in turn are those cases in which raising the labor income tax rate $t$ reduces labor effort. Here, the tipping point regarding the signs of all of these effects is $\rho=1$; when $\rho<$ 1 , the effects are as stated. For further details, see Kaplow (2006, 2008, 2015). In the discussion that follows, interpretations will emphasize this parameter range.

One can now ask: After the forced-savings constraint binds, is it fair to describe social security's forced savings requirement in this situation as akin to a tax levied on top of the income tax when individuals are myopic and naïve? The answer, clearly, is no. Although the signs of the effects on labor supply are the same, the magnitudes are not. When the constraint just binds (at which point $\alpha$ is already above zero), the magnitude of the forced-savings effect is zero, as 
explained just above. After that point, it is positive and rising, but it begins small and always involves the two competing (direct and indirect) effects. Therefore, its effect on labor supply tends to be smaller, and at least in ranges of modest forced savings, much smaller than that of an increase in $t$. The intuition is simple: a higher labor income tax rate reduces consumption in the present and in the future, whereas forced savings reduces consumption in the present and instead raises it in the future. And, even for myopic individuals, we have seen that the latter factor is important.

In summary, when individuals are myopic and their labor supply decisions are naïve in the sense described here, a forced-savings requirement has no effect on labor supply as the constraint just binds and (in the benchmark case examined) a negative effect thereafter, but one smaller in magnitude than the effect of a tax levied on top of the existing labor income tax. As suggested in the introduction, however, it is still possible that this effect on labor supply is important when designing a social insurance program. The reason is that even small effects on labor supply have a significant, first-order effect on welfare due to the presence of a large preexisting distortion of labor supply. Because of this fact, labor supply considerations could be substantial in designing an optimal program. Note, for example, that in our benchmark case, the optimal forced-savings requirement would be lower on the account of labor supply considerations: If there were no labor supply effect, the optimal $\alpha$ would be that which equates individuals' true marginal utilities of consumption (as given by the maximization of $u$, expression 1) between the present and the future (again, accounting for interest). Reducing the degree of forced savings from that point would cause no first-order loss regarding consumption allocation but would produce a first-order gain with regard to labor supply. Because this labor supply effect is important, the optimal reduction from the apparent consumption/savings determined ideal point could be significant.

\section{Social Security with Sophisticated Labor Supply}

In section B, it was supposed that our myopic individuals were naïve when choosing their labor supply, subject to the same myopic behavioral utility function $u^{M}$ that they use when (mis)allocating their disposable income between present and future consumption. Because there is no empirical evidence bearing directly on the labor supply decisions of myopic savers, it is prudent to consider as well an alternative assumption, one that (together with the first) helps to span a range of plausible situations.

In particular, and in parallel with other behavioral economics work, let us consider another natural case, which will be referred to as one with sophisticated, although myopic individuals. The idea is that, when choosing their labor supply, individuals are aware of and thus take into account that their subsequent allocations of consumption will reflect their myopia. Stated formally, they wish to maximize their true utility $u$ (expression 1) when choosing their labor supply, but take as given that their disposable income will be (mis)allocated in accordance

with their myopic utility function $u^{M}$ (expression 2). Indeed, it does not seem far-fetched to 
suppose that, when deciding whether to pursue higher education or when choosing or changing jobs (which may involve different salaries but correspondingly different effort requirements), individuals may adopt a more long-run, considered perspective. And, in the process, they may recognize that their subsequent earnings may be misallocated toward the present. ${ }^{10}$ Note that this sort of sophisticated behavior in the presence of myopia is in similar spirit to some individuals' use of commitment strategies with regard to savings (using automatic transfers to one's savings account, making elections for voluntary contributions to retirement accounts, abstaining from acquiring additional credit cards or taking out a home equity line of credit). And it is familiar in other settings as well (not keeping dessert around one’s home).

One again, no claim is being advanced with regard to how often in fact myopic savers behave in this fashion. Indeed, one might imagine that some individuals are naïve and others sophisticated, or that the same individual is sometimes naïve (forgoing remunerative overtime opportunities) and other times sophisticated (investing in higher education or moving to accept a higher-paying but more demanding job). Rather, this preliminary investigation aims to explore the implications of a range of plausible alternatives with regard to our important but largely unexamined feature of behavior: labor supply.

In contrast to the assumption that myopic individuals are naïve, sophistication has quite different, even opposite implications for labor supply. To foreshadow the analysis to follow, the core intuition is that sophisticated individuals welcome the fact that the government will make them save more than their myopic selves would do if left on their own, whereas naïve individuals perceive this paternalism as detrimental.

As before, consider first what happens as $\alpha$ is raised just to and past the point at which the forced-savings constraint (4) begins to bind. For our sophisticated individuals, moving the first (marginal) dollar from present to future consumption produces a significant utility gain. Because of their consumption/savings myopia, they are aware that too much consumption will occur in the present, suppressing the marginal utility of current consumption, and too little in the future, raising the marginal utility of retirement savings. Hence, the marginal dollar that is shifted from the present to the future reduces utility by far less in the current period than it raises utility later, a first-order utility gain. Moreover, this actual and perceived benefit continues, although to a decreasing extent, as $\alpha$ is raised ever further, until the point at which the level of forced savings just equals what a nonmyopic saver would optimally have selected.

What is the effect of this improvement - actual and perceived - in consumption allocation on labor supply? Again, we have a direct effect and an indirect effect, but the signs of

\footnotetext{
${ }^{10}$ Under another variation of sophistication, wherein individuals are not myopic when choosing labor supply but fail to foresee their own myopia, a binding forced-savings requirement will have no effect whatsoever on labor supply (assuming that $\alpha$ is not so high as to require even more savings than would be chosen by a nonmyopic, optimizing individual) for the simple reason that such individuals would not expect the forced-saving requirement to be binding on themselves (it requires less savings than they anticipate choosing on their own account).
} 
both effects are reversed from those in the preceding case with naïve individuals. For the sophisticated, the direct effect is positive. The fact that an additional dollar of disposable income will be allocated better on account of a stronger forced-savings requirement is beneficial and is regarded as such.

The indirect effect, however, is now negative. When consumption is badly misallocated (in one's mind, now) toward the present, marginal utility is lower in the present and higher in the future. For standard utility functions including that employed here, the latter effect is greater, which makes incremental earnings more valuable, all else equal. This means, however, that requiring greater forced savings reduces this difference and thereby reduces labor supply.

As in section B, we have opposed direct and indirect effects of greater forced savings on labor supply. And, as in the preceding case with naïve labor supply decisions, the direct effect is greater than the indirect effect when labor supply is upward sloping, that is, when a higher labor income tax rate reduces labor supply (our benchmark case for expositional purposes). The difference, however, is that the signs of the effects are reversed, so the sign of our net effect on labor supply reverses as well. In our benchmark case, raising the level of forced savings increases the labor supply of sophisticated (although myopic) individuals.

We also have another contrast with the prior case that was already mentioned: as the forced-savings requirement just begins to bind, we have a first-order (indeed, maximal) effect on sophisticated individuals, and thus at this point the positive labor supply effect is at its greatest. From the outset, sophisticated individuals realize that the forced-savings requirement is helping them, and the value of this assistance is largest when their misallocation is otherwise the largest, which is when the constraint just begins to bind. As forced savings are pushed ever higher, sophisticated individuals continue to benefit, and this further boosts their labor supply, although at an ever-decreasing rate, until the point at which forced savings equal optimal (nonmyopic) savings, where the effect is nil.

Another way to view these results is to return to our contrast with the introduction's illustration suggesting the possibility that social security might act like a tax levied on top of the existing income tax if individuals are sufficiently myopic. With sophisticated myopic individuals, the results contrast sharply. The effect on labor supply (in our benchmark case) is positive, not negative. This conclusion implies that a forced-savings requirement raises welfare much more than is the case when one focuses solely on the rectification of consumption misallocation. Also, a higher ordinary tax (whether levied on top of an existing tax or not) has ever increasing effects as its rate increases, whereas with sophisticated individuals, a higher forced-savings requirement (funded in essence by a payroll tax) has its greatest effect initially (when the constraint just begins to bind) and a decreasing effect thereafter. Accordingly, the tax upon a tax analogy is grossly misleading when myopic individuals are sophisticated with regard to their labor supply decisions. 


\section{Capital Taxation and Savings Subsidies}

In this section, we turn our attention from social security, which forces savings, to capital taxes and subsidies, which leave the savings decision to individuals but alter their incentive to save. In particular, just as we considered forced savings as a means of combating the effects of myopia, we now consider the use of retirement savings subsidies to soften the impact of myopia. As we will see, the conclusions regarding labor supply are quite similar.

To begin, let us return to our model of individuals' labor supply and savings decisions that was introduced in section A, and we will continue to assume that individuals' savings decisions are myopic in the same manner. Next, introduce in that model a tax or subsidy on savings. The two mechanisms are identical, except that they differ in sign. Note that, although the presence of myopia motivates interest in savings subsidies, such as exist in the United States for retirement savings, it is important to keep in mind that the same analysis more generally covers the taxation of capital income in the presence of myopia. The fact that such taxation is ordinarily debated on grounds unrelated to myopia in no way detracts from the fact that the presence of myopia both alters how it influences savings decisions and also, the focus here, how it influences labor supply, which will be qualitatively different from how it does so when individuals' behavior follows neoclassical assumptions. Therefore, the present section's analysis has important implications for policy questions that are not at all focused on possible deficiencies in individuals' savings decisions.

To introduce a capital tax or subsidy into section A's model, there are a number of equivalent methods that can be used. Capital taxes and subsidies are ordinarily taken to apply to the return on savings, $r$, but as is familiar from Atkinson and Stiglitz (1976), one can also view capital taxation or subsidization as involving differential taxation of second-period versus firstperiod consumption. All that matters for the savings decision is the relative effective tax rate on $c_{2}$ versus $c_{1}$. In contrast, any change in the average level of taxation of the two forms of consumption is equivalent to a change in the level of taxation on labor income. For example, if consumption taxation on average takes an additional $10 \%$ of disposable income, we could combine it with a reduction in the income tax rate that raised individuals' disposable income by a corresponding amount (here, roughly $11.1 \%$ so that, after the $10 \%$ of consumption taxation, the effective ability to consume is restored).

In examining the effect of capital taxation or subsidization on myopic individuals' consumption and, thereby, on labor income, it is useful to consider budget-neutral changes. (This formulation is analogous to our assumption in sections B and C that our forced-savings policy was actuarially fair, and hence neither raised nor reduced the present value of government revenue in the process of altering individuals' savings.) If, say, we consider a small subsidy on savings (second-period consumption), we can imagine simultaneously introducing a small tax on first-period consumption, or instead slightly raising the tax rate on labor income. In any event, our experiment is to introduce a small relative subsidy or tax on savings, with one of these other 
tax rates being adjusted in the background to raise the same level of revenue from our individual, under the hypothetical supposition that labor supply is unaffected. Having done so, we can then determine the effects on savings and on labor supply. ${ }^{11}$

Starting with savings, it is straightforward that introduction of a small subsidy will increase the fraction of income that our individual reserves for second-period consumption. This is true despite the presence of myopia. As explained in sections A and B, our myopic individual will choose an intermediate level of savings that maximizes $u^{M}$ (expression 2). At the individual's (perceived) optimum, the (overweighted) marginal utility of present consumption will be equated to the marginal utility of future consumption (taking into account that savings grow at the rate $r$ ).

When a small subsidy is introduced, future consumption becomes relatively more attractive and hence increases. Note that, if individuals ignored the subsidy and set aside the same fraction of income as before, future consumption would mechanically increase because our experiment provides a small subsidy to the amount saved (and also imposes a slight tax on the amount consumed in the first period). Whether future consumption rises by more or less than this mechanical effect depends on the curvature of the utility function. What matters for present purposes is that future consumption still rises. As with social security's forced savings, if this were the only effect, the subsidy would raise individuals' welfare on account of correcting their myopia to some degree. Similarly, a small capital tax, rather than a subsidy, would lower welfare because it would exacerbate the magnitude of consumption misallocation due to myopia.

Next, consider the effect of the introduction of a small capital subsidy on labor supply. (The impact of a small capital tax will be the opposite; hence, it will not be analyzed separately.) As with forced savings, we need to introduce a further assumption concerning how our myopic individuals view their labor supply decision. We will, as before, first consider naïve labor supply decisions and then sophisticated ones. In both cases, the results follow closely those with forced savings.

When myopic individuals' labor supply decisions are naïve - that is, when they choose labor supply to maximize the same myopic utility function, $u^{M}$ (expression 2), that governs their savings decisions - they regard any skew induced by differential taxation negatively. Note that this result is the same as when perfectly neoclassical optimizers face differential commodity taxation, including a relative tax or subsidy on savings. Despite this fact, when a small capital subsidy is just introduced, there is no effect on labor supply because the (perceived) consumption distortion is negligible. Just as when the social security forced-savings constraint begins to bind, individuals, despite their myopia, begin at a consumption allocation between the present and the future at which they have equated their (perceived) marginal utilities of consumption in the two time periods (accounting as well for the interest rate $r$ ). Hence, a slight deviation from this point

\footnotetext{
${ }^{11}$ For a formal statement of the set-up and the derivations, see Kaplow (2006, 2015).
} 
leads them to shift, say, a dollar across periods wherein the marginal utility of consumption is perceived to be the same. As a consequence, the marginal return to earning an additional dollar of disposable income is the same as it was before, so labor supply is unaffected. ${ }^{12}$

Next, suppose that individuals' labor supply decisions are sophisticated. In this case, they are aware of and like the consequences of a small capital subsidy. Specifically, they understand that, after earning their income, the capital subsidy will induce them to raise their future consumption. Moreover, as explained in section $\mathrm{C}$ for the situation when the forcedsavings constraint just begins to bind, they further appreciate that their myopia causes their future consumption to be too low. Therefore, when their deficient provision for the future will be induced to be set at a slightly higher level, this causes a first-order utility gain, which in turn makes additional labor effort more attractive than otherwise (in our benchmark case in which labor supply is upward sloping). Hence, under these assumptions, a small capital subsidy not only improves myopic individuals' consumption allocations, but it also raises social welfare as a consequence of the boost to labor effort.

To summarize, induced savings via a capital subsidy influence myopic individuals in much the same manner as does forced savings. Indeed, if one calibrates the two policies to result in the same small increase in future consumption - that is, if one compares (actuarially fair) social security when the forced-savings constraint just begins to bind with a small (revenueneutral) capital subsidy calibrated to induce an increase in future consumption of the same magnitude - all the effects will be precisely the same. Of particular relevance here, the same impact on future consumption translates into the same effect on labor supply, whatever that effect might be.

When individuals are myopic, we have seen that government policies that affect savings also may have important effects on labor supply, ones that can have even greater consequences for welfare than do the effects on savings that have heretofore been the focus of policy analysis. These conclusions validate the introduction's suggestion that the interaction with labor supply merits considerable attention. Note further, however, that in none of the cases considered social security forced savings or capital taxation and subsidization, and with naïve or sophisticated labor supply behavior - does the effect on labor supply resemble that of a tax levied on top of an existing tax (here, the income tax). Indeed, with sophisticated labor supply behavior, both savings promotion policies raise rather than lower labor supply in our benchmark case.

\footnotetext{
${ }^{12}$ As is common in analyzing optimal tax problems, the analysis becomes more complicated once one moves away from the neighborhood of an infinitesimal change from no differential taxation. The further effects described in section B after the forced-savings constraint has begun to bind would remain applicable here, but additional complications would be introduced by the fact that individuals' consumption shifts would then have a first-order effect on commodity tax revenue that would need to be taken into account.
} 


\section{Targeted Savings}

Let us now turn from part II's analysis of myopia to a variety of other non-neoclassical forms of savings behavior, specifically, ones that may be captured by the notion of targeted savings. ${ }^{13}$ Our myopic individuals were assumed to engage in optimization. And, in a more realistic model with many periods and uncertainty in labor earnings, in the return on investment, and other factors, they would need to undertake highly complex optimization - the effect of myopia being that the optimization is performed with excessive weight on present consumption. As the introduction suggests, however, there is a concern that, with regard to savings decisions, individuals' behavior may not be well characterized by complex optimization, neoclassical or myopic.

If optimization is not taking place, however, we are left with the question of how individuals do in fact make their savings decisions. This part assumes that individuals' savings are set at some target fraction of disposable income. Such a target may derive from a number of sources. It could, again, be social security: the government has set a target, and the individual may save that much (via social insurance) and no more. Instead or in addition, an employer may contribute to a retirement plan, and the individual may take that as the appropriate amount. Or the individual may be defaulted into a level of employee contributions and stick with that amount, as some empirical evidence suggests tends to occur. Or an individual may obtain advice from experts, friends, the Internet, or elsewhere and then save the recommended amount, without necessarily understanding why that target is optimal. Or an individual may simply follow some habit, although this assumption raises the question of how the habit was developed. (The answer could be one of the foregoing, or it could reflect a previous attempt at optimization, the rationale underlying the bottom line having been forgotten.)

To analyze the effect of targeted savings behavior on labor supply, we will again refer to the two-period model introduced in section II.A. With regard to savings, we are supposing, as stated, that individuals simply meet their target, which we may conveniently designate as saving the fraction $\alpha$ of their income, leaving the fraction 1- $\alpha$ for present consumption. Therefore, their present consumption, $c_{1}$, is given by expression (4), where we now suppose (as when the forcesavings constraint was binding) that it is satisfied as an equality.

This brings us to our question of interest: How do such individuals determine their labor supply? We might imagine that they optimize, maximizing their utility function $u$ (now, without myopia), as indicated by expression (1), subject to the budget constraint (3) and the savings target (expression 4, satisfied as an equality). But this supposes that individuals can undertake the necessary analysis and, in particular, ascertain whether their savings rate $\alpha$ is optimal and,

\footnotetext{
${ }^{13}$ For formal elaboration of the analysis in this part, see Kaplow (2011).
} 
furthermore, determine the implication for the weighted-average marginal utility of additional disposable income if it is not. But such would be out of spirit with the present analysis. ${ }^{14}$

Consistent with our reasoning that supposes that targeted savers are not engaging in this optimization process, we need to make some alternative assumptions about labor supply behavior that are motivated by our analysis of savings decisions. In this part, three different assumptions will be analyzed. Again, in the absence of empirical evidence, these choices are considered on grounds of some a priori plausibility (at least as part of the explanation for some individuals' behavior) and because they span a wide range of possibilities regarding labor supply. The first two are rather simple, and the third a bit more complex but also interesting and having some appeal in light of the explanations offered for targeted savings.

First, assume that individuals, when choosing their labor supply, regard the portion of their income that will be saved as if it vanishes. This might be appealing with regard to social security, employer contributions to retirement plans, or even employee contributions, particularly when they are the consequence of a default. The idea is that, once the savings decisions are set, individuals ignore the savings entirely. Put another way, they gauge their return from work by looking at their paycheck, the amount that they can actually consume in the present. In essence, their labor supply decisions trade off the marginal utility of greater current consumption (alone) with the disutility of additional labor effort. In this case - and it is the only such case considered in this essay - the effect of a higher savings target on labor supply is equivalent to that of an additional tax levied on top of the existing labor income tax. Although the resulting increase in savings goes into an account, to fund future consumption, rather than to the government, we are supposing that individuals ignore this account when making their labor supply decisions. In our benchmark case of an upward sloping labor supply curve, in which an income tax reduces labor supply, a higher savings target causes a further reduction, and the net distortion begins (from a savings target of zero) with a significant initial distortion due to the pre-existing income tax. In this case (only), targeted savings indeed acts like raising a tax on top of the existing income tax.

Second, assume instead that individuals appreciate that the saved funds are theirs, which is plausible under many of our stories for targeted savings (particular those in which they themselves choose the target). Nevertheless, they are nonoptimizers, we are supposing, and let us assume further that, not really knowing how to evaluate the marginal benefit of additional savings, they (for lack of an alternative) view it as if it was additional current consumption, something they can understand. In this case, a higher savings target has no effect on labor supply. Individuals, when choosing labor effort, are now in essence trading off the marginal utility of additional (current) consumption with the marginal disutility of additional labor. But

\footnotetext{
${ }^{14}$ It would be tantamount to determining how inducing a savings distortion influences the labor supply of neoclassical optimizers - a rather different question. For completeness, it may be noted that, in the present model, such a distortion of savings has no first-order effect on labor supply when it is infinitesimal, but suppresses labor supply (in our benchmark case with an upward sloping labor supply curve) when savings is either too high or too low.
} 
this is just how they would have treated additional earnings if the additional increment to savings was instead immediately consumed. Hence, under this second assumption, labor supply may properly be ignored (as it implicitly has been in much of the literature, although without explicit justification).

Third, assume that individuals act as if their target savings rate was chosen paternalistically, in the best sense of the term, which is to say with their best interest at heart. That is, we are now imagining the individuals, who themselves are incapable of explicit optimization, are acting on the belief that, whoever set their savings target, this was the result of someone having determined (perhaps approximately) the appropriate amount to save. This might be imagined to be true with respect to a government-designed social security program, an employer's chosen level of retirement plan contributions and/or a default employee contribution rate, or the advice of an investment expert.

Consider now the implication of this assumption for labor supply. ${ }^{15}$ As in the prior cases, we are supposing that individuals do understand the marginal utility of present consumption. Hence, if they earn an additional dollar of disposable income, they know that 1- $\alpha$ of that amount will be currently consumed, thereby raising their utility by 1- $\alpha$ times the marginal utility of current consumption. And what about the fraction $\alpha$ that is saved? Because our individual assumes that the target was set optimally, it follows that the paternalistic target-setter equated the marginal utility of present consumption with the marginal utility of future consumption (taking into account that savings earn interest at the rate $r$ ). Hence, they evaluate the marginal utility of the amount saved at $\alpha$ times the marginal utility of current consumption. Summing these two benefits - the former weighted by 1- $\alpha$ and the latter by $\alpha$ - the value of an additional dollar of disposable income simply equals the marginal utility of an additional dollar of current consumption. This is the value that the individual will equate to the marginal disutility of labor effort.

From this analysis, it is straightforward to determine the effect of raising the savings target $\alpha$ on labor supply. A higher savings target reduces current consumption. Lower current consumption implies that the marginal utility of current consumption is higher. And, as just explained, it is this (now higher) marginal utility of current consumption that the individual equates to the marginal disutility of labor. Hence, labor effort rises because earnings are seen as more attractive than otherwise. (Consider the following more intuitive restatement: When the paternalistic target-setter chooses a higher savings target, the individual gets the message that consumption in the future is regarded to be more valuable; therefore, after the resulting reallocation, incremental disposable income - consumed some in the present and some in the future - is more valuable overall.) That is, we have an unambiguous result that raising the savings target raises labor supply, which, as explained throughout, means a reduction in the preexisting distortion of labor. This case presents quite a contrast with the effect of an increase in

\footnotetext{
${ }^{15}$ For a formal statement, see Kaplow (2011).
} 
the labor income tax on labor supply even though both involve a reduction in the disposable income available for current consumption. ${ }^{16}$

Bringing these three cases together, a higher savings target may reduce labor supply (case one, under our benchmark assumption of a rising labor supply curve), have no effect (case two), or raise labor supply (case three). One could also consider cases in which individuals' translation of a savings target into a labor supply decision falls between various of these assumptions. For example, if behavior is a mix of cases one and two - individuals to some extent treat their targeted savings as if they vanish, but realize that they are not truly gone and hence behave as if some portion were consumed currently, lacking another way to think about the matter - then a higher savings target would reduce labor supply (under our benchmark assumption), but not by so much as would a tax levied atop the existing income tax. And if they mix cases two and three, labor supply would increase, but less so than in the third case.

These possibilities span a wide range of labor supply effects, which, as explained previously, can be highly consequential when evaluating savings policies. It is important, as with myopia in part II, to ascertain empirically which assumptions, or combinations thereof, are true, and for how many individuals. It would not be surprising if some individuals' labor supply decisions fit each of these cases. And it is also possible that still other explanations may govern the behavior of many. In addition, we do not know how many individuals are influenced by myopia, instead of or in addition to the motivations postulated in this part of the essay, again indicating the need for empirical investigation of the relationship between non-neoclassical savings behavior and labor supply.

\section{Discussion}

\section{A. Choice Among Savings Policies}

A variety of policies, including a social insurance forced-savings requirement, retirement savings subsidies, and default savings rules have been proposed to address possible savings deficiencies. If all individuals were identical with respect to their suboptimal savings behavior, the choice among policies with regard to their effects on savings may be straightforward, and in some cases a matter of indifference - namely, if they induce the same level of savings. If individuals both are myopic with regard to savings and also are inattentive, defaults would stick and have much the same effect as forced savings. But if, for example, many myopic individuals eventually noticed how large their voluntary withholding was, they may then reduce their savings, an option that is unavailable if savings is forced.

\footnotetext{
${ }^{16}$ To elaborate briefly, a higher labor income tax has both an income and a substitution effect (and, in our benchmark case, we are supposing that the substitution effect dominates). Here, it turns out that the present assumption of a paternalistically set savings target implies that a higher target is akin to a "tax" that has only an income effect, which unambiguously raises labor effort.
} 
More plausibly, individuals vary a great deal in their infirmities. Suppose, for example, that part of the population is myopic and the other part saves optimally (and assume that individuals are identical in other respects). In that case, forced savings, as long as not in excess of the optimal level of savings, would raise the savings of the first group and have no effect on the second. By contrast, a subsidy large enough to boost significantly the savings of the myopic would induce excessive savings by the neoclassical optimizers, producing lower welfare for them. Of course, if individuals' savings needs vary, more flexibility may be advantageous. But not necessarily, because myopic individuals may be precisely the ones who opt out of the policies aimed at them.

Similar ideas seem relevant to targeted savings. If everyone behaved identically, the optimal policy, looking solely at effects on savings, would target the right savings level and be the one most likely to be followed. But if there is heterogeneity, the question becomes whether different targets can be set for different groups reflecting their different needs. This might be possible because in this instance there is not assumed to be any myopia, so individuals may be inclined to follow clear recommendations. In addition, targets may be customized for different age groups or family configurations.

The focus of this essay, however, is not on how optimally to design savings policies with regard to savings. Instead, the concern is with how such policy analysis might need to be altered in light of labor supply effects. In the analysis in parts II and III, however, the presence, direction, and strength of labor supply effects depended fundamentally on the nature of individuals' deficiencies in savings behavior, whether they were naïve or sophisticated in the case of myopia, and how they regarded their savings in the case of targeted savings - as well as on how large the savings requirements or targets were. Capital subsidies and forced savings have the same labor supply effects when individuals are myopic, and targeted savings was imagined to have one or another effect without regard to what policy implemented a particular target. At the level of abstraction employed in this preliminary investigation, and in the absence of empirical evidence, it is difficult to speculate on how different forms of policies that achieve similar levels of savings might differ with regard to labor supply.

It is also interesting to contemplate heterogeneity in labor supply reactions within a given mode of savings behavior. ${ }^{17}$ Even if everyone were equally myopic, for example, the labor supply decisions of some may be naïve and others sophisticated. Because the former involve reduced labor supply and the latter increased labor supply, it would be optimal, if feasible, to set a higher level of required savings for the latter than for the former. Or with targeted savings, even if everyone's savings needs were identical, different savings targets would be optimal for those whose labor supply is determined in different ways. Unfortunately, even if there was empirical evidence on the fraction of individuals whose labor supply is determined in a particular

\footnotetext{
${ }^{17}$ Additional aspects of heterogeneity, including the possibility that savings policies may redistribute (for a given income level) between the myopic and nonmyopic, are explored in Kaplow (2006, 2008, 2015).
} 
fashion, such differences would probably be unobservable. This raises the question whether some set of policies could be devised that would induce individuals to sort in a favorable manner. Otherwise, savings targets would need to be set in ways that trade off the divergent welfare effects across individuals.

\section{B. Liquidity Constraints}

It is familiar that liquidity constraints may bear on the desirability of savings policies, particularly those that force savings early in the lifecycle, for example, for individuals with rising earnings profiles, with needs for capital to start a business, to buy a home, or to finance consumption when there are children in the household. See, for example, Hubbard and Judd (1987). It should be noted, however, that the problem looks different when individuals' savings decisions may be suboptimal. Notably, in the presence of myopia, liquidity constraints may help to limit the extent of undersavings (including excessive borrowing), as suggested by Laibson (1997). In addition, this point implies that empirical evidence of liquidity constraints should be treated with caution because, if seemingly constrained individuals are myopic, the degree to which the constraints reduce their welfare may be less, and it is also possible that they raise welfare. Furthermore, some individuals may seek to arrange their lives to make borrowing difficult as a self-control device; that is, what seem to be constraints may be the result of conscious choice.

The main implication of liquidity constraints is that they act as a floor on savings (including, as mentioned, on the magnitude of negative savings, i.e., borrowing). This minimum is relevant to assessing all manner of policies toward savings, and, to the extent that the magnitude of savings is thereby altered, labor supply effects would differ accordingly. It does not seem clear, however, that, for a given behavioral utility function - with regard to savings and labor supply - there are any further implications for labor supply.

\section{Other Forms of Social or Employer-Provided Insurance}

Throughout this essay, the focus has been on policies aimed at adequate provision for retirement savings, a major component of social insurance programs. Other dimensions of social insurance, however, may be subject to similar analysis. In addition to adverse selection and other factors, part of the reason that individuals may not, on their own, choose the optimal level of health, disability, unemployment, or life insurance may be the same sorts of behavioral limitations considered here (and in the broader literature) with regard to savings. ${ }^{18}$ For example, myopic individuals may be disinclined to reduce current consumption in order to fund insurance premiums that cover future adverse shocks. Other behavioral phenomena, such as overoptimism, may similarly lead to inadequate provision. Likewise, for individuals who do purchase insurance

\footnotetext{
${ }^{18}$ Behavioral infirmities may also supplement adverse selection (e.g., Brown, Mitchell, and Poterba (2002) and Finkelstein and Poterba (2004)) and other factors in helping to explain individuals' failure adequately to annuitize. See Davidoff, Brown, and Diamond (2005) and Brown et al. (2013).
} 
- including quite importantly, those who receive insurance as part of their standard employment benefits package - optimization may be incomplete or absent: just as we examined targeted savers in part III, we can imagine individuals whose insurance decisions reflect targets set by others.

In all of these instances, as a first cut at the problem, it seems that the same analysis of labor supply should be applicable. Just as labor supply may be important for retirement savings policies, so it may affect the social welfare impact of social or employer-provided insurance more broadly. The amounts that individuals pay each year - through payroll taxes or employers offering lower cash wages - are substantial, and these premiums may have modest or large effects on labor supply that may be positive or negative depending on what we assume about how individuals' labor supply is determined. One could in a sense reinterpret the model and logic in parts II and III for this case, and the same conclusions would follow. ${ }^{19}$ Of course, individuals' perceptions and thus behavior - with regard to insurance itself and to the labor supply decision - need not be the same as their perceptions and behavior with regard to retirement savings. Hence, this broader framing of the problem suggests the need for a correspondingly broader empirical program addressed to the labor supply effects of social insurance - and employer-provided insurance as well.

\section{Conclusion}

This essay presents a preliminary conceptual investigation of the labor supply effects of government policies aimed at savings in a world in which individuals' savings decisions depart from the neoclassical model. The importance of the problem is suggested by the confluence of a number of considerations: evidence on myopic and otherwise suboptimal savings behavior, major government policies that are premised on this phenomenon, the inconsistency between such savings behavior and maintaining neoclassical assumptions regarding labor supply, and the significant pre-existing labor supply distortion due to income taxation and other policies, which renders even modest side-effects on labor supply of first-order importance.

The greatest challenge in undertaking this exercise is in choosing assumptions regarding labor supply. On one hand, neoclassical assumptions are incoherent or at least in tension with the maintained assumptions that generate suboptimal savings behavior. On the other hand, little empirical evidence is available to inform our understanding of how labor supply decisions are actually made in these settings. In light of this challenge, a range of plausible assumptions was considered.

\footnotetext{
${ }^{19}$ Note that, just as optimal savings decisions equate marginal utilities (adjusted for the interest rate) across time periods, so optimal insurance decisions equate marginal utilities across states of nature.
} 
For myopic savings, we examined individuals whose labor supply decisions were either naïve (following the same myopic utility function that determines their consumption allocation decisions) or sophisticated (recognizing that their earnings will be misallocated toward the present). In the benchmark case considered (with upward sloping labor supply), effects on labor supply were quite different. For naïve myopic individuals, pushing up savings had no effect on labor supply initially and negative effects thereafter. But for sophisticated myopic individuals, pushing up savings initially had a first-order and positive effect on labor supply, the magnitude of which diminished thereafter.

For target savers - those who are content with savings targets established by others - we considered three ways in which these nonoptimizers may treat the resulting savings when choosing labor supply. If they regard their savings as nonexistent (they just look at their takehome pay), a higher savings target affects labor supply in the same manner as would a tax levied on top of the existing labor income tax. If they view their savings as generating the same utility as would correspondingly greater current consumption, a higher savings target has no effect on labor supply. And if they view their savings target as having been determined (by the government, their employer, or an investment advisor) in their own best interests (even without individuals understanding how such calculations were made), then a higher savings target unambiguously raises labor supply.

Because of the large pre-existing distortion of labor supply, savings policies that have even modest labor supply effects could impose a large welfare cost if labor effort is reduced. But if it is increased, the aggregate welfare impact would be much more favorable than otherwise. Accordingly, the present analysis suggests that optimal savings targets may be much lower, or much higher, than would be the case under existing analysis that confines attention to resulting levels of savings.

In summary, we have learned that we may need to make significant adjustments to savings policies, but we do not know in what direction, of what magnitude, or under what circumstances. The analytical conclusions of this investigation therefore suggest that there is great value in pursuing a broadened empirical research agenda. It needs to address explicitly the implications for labor supply of various forms of suboptimality in savings decisions - and of policies aimed at their correction. ${ }^{20}$

\footnotetext{
${ }^{20}$ Additional avenues are also suggested. One area would be to enrich the analytical model, such as by allowing additional periods of labor supply (to analyze how optimal savings policy, interacted with labor supply, may vary over the lifecycle, and also to incorporate retirement decisions), introducing nonconstant wage profiles (particularly relevant for those who are liquidity constrained, examined briefly in section IV.B), and modeling uncertainty concerning both future labor income and the return to savings. Another avenue would examine other individual infirmities with respect to savings decisions as well as other rationales for forced savings, such as the Samaritan's dilemma (Buchanan 1975) - specifically with regard to their implications for labor supply. See Kaplow (2008).
} 


\section{References}

Aguiar, Mark, and Erik Hurst. 2005. “Consumption versus Expenditure.” Journal of Political Economy 113, no. 5:919-48.

Aguiar, Mark, and Erik Hurst. 2007. "Life-Cycle Prices and Production.” American Economic Review 97, no. 5:1533-59.

Atkinson, Anthony B. and Joseph E. Stiglitz .1976. "The Design of Tax Structure: Direct Versus Indirect Taxation.” Journal of Public Economics 6, no.:1-2:55-75.

Auerbach, Alan J., and Laurence J. Kotlikoff .1987. Dynamic Fiscal Policy. Cambridge: Cambridge University Press.

Banks, James, Richard Blundell, and Sarah Tanner. 1998. "Is There a Retirement-Savings Puzzle?” American Economic Review 88, no. 4:769-88.

Bateman, Hazel, Geoffrey Kingston, and John Piggott. 2001. Forced Saving: Mandating Private Retirement Incomes. Cambridge: Cambridge University Press.

Bernheim, B. Douglas. 1994. "Personal Saving, Information, and Economic Literacy: New Directions for Public Policy.” In Tax Policy for Economic Growth in the 1990s, ed. C.E. Walker, M. Bloomfield, and M. Thorning, 53-78. Washington, D.C.: American Council for Capital Formation.

Bernheim, B. Douglas. 2002 “Taxation and Saving.” In Handbook of Public Economics, vol. 3, ed. Alan J. Auerbach and Martin Feldstein, 173-1249. Amsterdam: North-Holland.

Bernheim, B. Douglas, and Antonio Rangel. 2007. "Behavioral Public Economics: Welfare and Policy Analysis with Nonstandard Decision-Makers.” In Behavioral Economics and Its Applications, ed. P. Diamond and H. Vartiainen, 7-77. Princeton: Princeton University Press.

Bernheim, B. Douglas, Jonathan Skinner, and Steven Weinberg. 2001. "What Accounts for the Variation in Retirement Wealth among U.S. Households?” American Economic Review 91, no. 4:832-57.

Beshears, John, James J. Choi, David Laibson, and Brigitte C. Madrian. 2008. "The Importance of Default Options for Retirement Savings Outcomes: Evidence from the United States.” In Lessons from Pension Reform in the Americas, ed. Stephen J. Kay and Tapen Sinha, 59-87, Oxford: Oxford University Press.

Beshears, John, James J. Choi, David Laibson, and Brigitte C. Madrian. 2013. "Simplification and Saving." Journal of Economic Behavior and Organization 95:130-45.

Brown, Jeffrey R., Arie Kapteyn, Erzo F.P. Luttmer, and Olivia S. Mitchell. 2013. “Decision Complexity as a Barrier to Annuitization.” Working Paper no. 19168, NBER, Cambridge, MA.

Brown, Jeffrey R., Olivia S. Mitchell, and James M. Poterba. 2002. "Mortality Risk, Inflation Risk, and Annuity Products.” In Innovations in Retirement Financing, ed. Olivia S. Mitchell, Zvi Bodie, P. Brett Hammond, and Stephen Zeldes, 75-97. Philadelphia: University of Pennsylvania Press. 
Browning, Edgar K. 1985. “The Marginal Social Security Tax on Labor.” Public Finance Quarterly 13, no. 3:227-51.

Buchanan, James M. 1975. “The Samaritan’s Dilemma.” In Altruism, Morality, and Economic Theory, ed. Edmund S. Phelps, 71-85. New York: Russell Sage Foundation.

Burkhauser, Richard V., and John A. Turner. 1978. “A Time-Series Analysis on Social Security and Its Effect on the Market Work of Men at Younger Ages.” Journal of Political Economy 86, no. 4:701-15.

Burkhauser, Richard V. and John A. Turner. 1985. "Is the Social Security Payroll Tax a Tax?” Public Finance Quarterly 13, no. 3:253-67.

Carroll, Gabriel D., James J. Choi, David Laibson, Brigitte C. Madrian, and Andrew Metrick. 2009. “Optimal Defaults and Active Decisions.” Quarterly Journal of Economics 124, no. 4:1639-74.

Chetty, Raj. 2006. “A New Method of Estimating Risk Aversion.” American Economic Review 96, no. 5:1821-34.

Chetty, Raj., John N. Friedman, Søren Leth-Petersen, Torben Heien Nielsen, and Tore Olsen. 2014. “Active vs. Passive Decisions and Crowd-Out in Retirement Savings Accounts: Evidence from Denmark.” Quarterly Journal of Economics 129, no. 3: 1141-1219.

Choi, James J., David Laibson, Brigitte C. Madrian, and Andrew Metrick. 2004. "For Better of Worse: Default Effects and 401(k) Savings Behavior.” In Perspectives on the Economics of Aging, ed. David A. Wise, 81-121. Chicago: University of Chicago Press.

Davidoff, Thomas, Jeffrey R. Brown, and Peter A. Diamond. 2005. “Annuities and Individual Welfare.” American Economic Review 95, no. 5:1573-90.

Diamond, Peter A. 2002. Social Security Reform. Oxford: Oxford University Press.

Diamond, Peter A. 2004. "Social Security.” American Economic Review 94, no. 1:1-24.

Diamond, Peter A., and Botond Köszegi. 2003. "Quasi-Hyperbolic Discounting and Retirement.” Journal of Public Economics 87, no. 9-10:1839-72.

Engen, Eric M., William G. Gale, and Cori E. Uccello. 1999. “The Adequacy of Household Saving.” Brookings Papers on Economic Activity, no. 2:65-187.

Feldstein, Martin. 1985. “The Optimal Level of Social Security Benefits.” Quarterly Journal of Economics 100, no. 2:303-20.

Feldstein, Martin, and Jeffrey B. Liebman. 2002. “Social Security.” In Handbook of Public Economics, vol. 4, ed. Alan J. Auerbach and Martin Feldstein, 2245-2324. Amsterdam: North-Holland:.

Finkelstein, Amy, and James Poterba. 2004. “Adverse Selection in Insurance Markets: Policyholder Evidence from the U.K. Annuity Market.” Journal of Political Economy 112, no. 1:183-208.

Fullerton, Don. 1991. "Reconciling Recent Estimates of the Marginal Welfare Cost of Taxation.” American Economic Review 81, no. 1:302-08.

Gokhale, Jagadeesh, Laurence J. Kotlikoff, and Mark J. Warshawsky. 2001. "Comparing the Economic and Conventional Approaches to Financial Planning.” In Essays on Saving, 
Bequests, Altruism, and Life-Cycle Planning, ed. Laurence J. Kotlikoff, 489-560. Cambridge: MIT Press.

Gordon, Roger H. 1983. "Social Security and Labor Supply Incentives.” Contemporary Policy Issues no. 3:16-22.

Hubbard, R. Glenn, and Kenneth L. Judd. 1987. "Social Security and Individual Welfare: Precautionary Saving, Borrowing Constraints, and the Payroll Tax.” American Economic Review 77, no. 4:630-46.

Johnson, Stephen, Laurence J. Kotlikoff, and William. Samuelson. 2001. "Can People Compute? An Experimental Test of the Life Cycle Consumption Model.” In Essays on Saving, Bequests, Altruism, and Life-Cycle Planning, ed. Laurence J. Kotlikoff, 335-85. Cambridge: MIT Press.

Kaplow, Louis. 2006. "Myopia and the Effects of Social Security and Capital Taxation on Labor Supply.” Working Paper no. 12452, NBER, Cambridge, MA.

Kaplow, Louis. 2008. The Theory of Taxation and Public Economics. Princeton: Princeton University Press.

Kaplow, Louis. 2011. “Targeted Savings and Labor Supply.” International Tax and Public Finance 18:507-18.

Kaplow, Louis. 2015. "Myopia and the Effects of Social Security and Capital Taxation on Labor Supply." National Tax Journal 68, no. 1:7-32.

Kotlikoff, Laurence J., Avia Spivak, and Lawrence H. Summers. 1982. "The Adequacy of Savings.” American Economic Review 72, no. 5:1056-69.

Laibson, David. 1996. "Hyperbolic Discount Functions, Undersaving, and Savings Policy.” Working Paper no. 5635, NBER, Cambridge, MA.

Laibson, David. 1997. “Golden Eggs and Hyperbolic Discounting.” Quarterly Journal of Economics 112, no. 2:443-77.

Liebman, Jeffrey B., and Erzo F.P. Luttmer. 2012. "The Perception of Social Security Incentives for Labor Supply and Retirement: The Median Voter Knows More Than You'd Think.” In Tax Policy and the Economy, vol. 26, ed. Jeffrey R. Brown, 1-42.

Liebman, Jeffrey B., and Richard J. Zeckhauser. 2004. "Schmeduling.” (Unpublished manuscript.)

Madrian, Brigitte C., and Dennis F. Shea. 2001. "The Power of Suggestion: Inertia in 401(k) Participation and Savings Behavior.” Quarterly Journal of Economics 116, no. 4:114987.

Moffitt, Robert A. 1987. "Life-Cycle Labor Supply and Social Security: A Time-Series Analysis.” In Work, Health, and Income among the Elderly, ed. Gary Burtless, 183-220. Washington, D.C.: Brookings Institution.

Moore, James, and Olivia S. Mitchell. 2000. "Projected Retirement Wealth and Saving Adequacy.” In Forecasting Retirement Needs and Retirement Wealth, ed. Olivia S. Mitchell, P. Brett Hammond, and Anna M. Rappaport, 68-94. Philadelphia: University of Pennsylvania Press. 
Scholz, John Karl, Ananth Seshadri, and Surachai Khitatrakun. 2006. "Are Americans Saving 'Optimally' for Retirement?” Journal of Political Economy 114, no. 4:617-43.

Smith, Sarah. 2006. "The Retirement-Consumption Puzzle and Involuntary Early Retirement: Evidence from the British Household Panel Survey.” Economic Journal 116, no. 510:C130-48.

Strotz, Robert H. 1956. “Myopia and Inconsistency in Dynamic Utility Maximization.” Review of Economic Studies 23, no. 3:165-80.

Thaler, Richard H., and Shlomo Benartzi. 2004. "Save More Tomorrow: Using Behavioral Economics to Increase Employee Saving.” Journal of Political Economy 112, no. 1, pt. 2:S164-87. 